\title{
Effects of insulin on renal haemodynamics and the proximal and distal tubular sodium handling in healthy subjects
}

\author{
P.Stenvinkel ${ }^{1}$, J. Bolinder $^{2}$ and A. Alvestrand ${ }^{1}$ \\ Departments of ${ }^{1}$ Renal Medicine and ${ }^{2}$ Internal Medicine, Huddinge University Hospital, Karolinska Institute, Stockholm, Sweden
}

\begin{abstract}
Summary. The effects of insulin on renal haemodynamics and renal sodium handling were studied in 10 healthy males. Using the euglycaemic insulin clamp technique, insulin was infused on separate days resulting in two levels of hyperinsulinaemia ( $41 \pm 3$ and $90 \pm 7 \mathrm{mU} / 1$, respectively). Renal haemodynamics and the proximal and distal tubular sodium handling were studied using inulin, para-amino-hippuric acid, sodium and lithium clearances. Low- and high-dose insulin infusions were followed by a fall in sodium clearance from $1.6 \pm 0.1 \mathrm{ml} / \mathrm{min}$ to $1.2 \pm 0.1$ and $1.0 \pm 0.1 \mathrm{ml} / \mathrm{min}$, respectively. Both levels of hyperinsulinaemia resulted in increased distal tubular sodium reabsorption. The distal antinatriuretic effect of insulin was associated with dose- and time-dependent decline in proximal tubular sodium reabsorption. The changes in proximal tubu-
\end{abstract}

lar sodium handling occurred without any significant changes in natriuretic factors, such as renal dopamine and plasma atrial natriuretic peptide levels. However, hyperinsulinaemia resulted in time- and dose-dependent increases in renal plasma flow, and renal vasodilatation could, possibly via changes in renal interstitial pressure, have contributed to the fall in the proximal tubular sodium reabsorption. The results also suggest that decreased proximal sodium reabsorption may be a compensatory mechanism counteracting the insulin-induced sodium retention.

Key words: Exogenous insulin infusion, sodium excretion, lithium clearance, renal haemodynamics, renal dopamine, atrial natriuretic peptide.
The antinatriuretic effect of insulin is well documented, and most studies indicate that acutely-induced hyperinsulinaemia produces its antinatriuretic effect by stimulating sodium reabsorption in the distal tubule [1-4]. However, conditions characterized by hyperinsulinaemia, such as essential hypertension and obesity are not characterized by increased total body exchangeable sodium, which suggests that the antinatriuretic effect of insulin is transient. It therefore seems likely that compensatory mechanism(s), counteracting the acute stimulatory effects of insulin on distal tubular sodium reabsorption become operative. In a micropuncture study in dogs, using high physiological to supraphysiological insulin levels, DeFronzo et al. [1] observed that insulin-stimulated distal sodium reabsorption was associated with a decreased sodium reabsorption in the proximal tubule. One can speculate that decreased proximal sodium reabsorption may be a compensatory mechanism counteracting the insulin-induced sodium retention. We therefore wished to determine whether sodium retention induced by physiological hyperinsulinaemia in man is accompanied by changes in proximal sodium handling. Using the euglycaemic hyperinsulinaemic clamp technique and lithium clearance, we investigated the effects of two levels of hyperinsulinaemia on renal tubular sodium handling. The effects of hyperinsulinaemia on factors which may mediate proximal tubular natriuresis, such as changes in renal haemodynamics and natriuretic factors, including renal dopamine and plasma atrial natriuretic peptide levels, were also investigated.

\section{Subjects and methods}

\section{Subjects}

Ten healthy males aged $27-36$ years (mean age $32.8 \pm 0.9$ years) were studied. All were normotensive and none was on medication. The subjects were advised to continue their usual diets and were maintained on an ad libitum sodium and protein diet prior to the studies. Their mean body mass index was $23.5 \pm 0.5 \mathrm{~kg} / \mathrm{m}^{2}$ (range $\left.21.8-26.2 \mathrm{~kg} / \mathrm{m}^{2}\right)$. All subjects gave their informed consent and approval was obtained from the local ethics committee.

\section{Methods}

The subjects received $16.2 \mathrm{mmol}$ of lithium orally, as lithium carbonate, the evening before the clearance study, and then fasted overnight. On the morning of the investigation they drank $500 \mathrm{ml}$ of tap 
Table 1. Effects of insulin infusions on plasma insulin, C-peptide, blood glucose, heart rate and blood pressure

\begin{tabular}{|c|c|c|c|}
\hline & Basal & Low-dose insulin & High-dose insulin \\
\hline Plasma insulin (mU/l) & $12 \pm 1$ & $41 \pm 3^{b}$ & $90 \pm 7^{b}$ \\
\hline C-peptide (nmol/) & $0.50 \pm 0.04$ & $0.34 \pm 0.04^{b}$ & $0.34 \pm 0.04^{b}$ \\
\hline Plasma glucose $(\mathrm{mmol} / \mathrm{l})$ & $4.5 \pm 0.1$ & $4.5 \pm 0.2$ & $4.6 \pm 0.1$ \\
\hline Heart rate (beats/min) & $54 \pm 2$ & $58 \pm 2$ & $59 \pm 4^{a}$ \\
\hline Systolic blood pressure $(\mathrm{mm} \mathrm{Hg})$ & $111 \pm 2$ & $113 \pm 4$ & $116 \pm 2$ \\
\hline Diastolic blood pressure (mm Hg) & $72 \pm 2$ & $74 \pm 4$ & $74 \pm 1$ \\
\hline Mean blood pressure $(\mathrm{mm} \mathrm{Hg})$ & $85 \pm 1$ & $87 \pm 4$ & $88 \pm 1$ \\
\hline
\end{tabular}

Mean \pm SEM indicated

${ }^{a} \mathrm{p}<0.05$ vs basal and ${ }^{b} \mathrm{p}<0.01$ vs basal

Table 2. Effects of insulin infusions on plasma renin activity, serum catecholamines, urinary dopamine and atrial natriuretic peptide

\begin{tabular}{lccc}
\hline & Basal & Low-dose insulin & High-dose insulin \\
\hline Plasma renin activity $(\mu \mathrm{g} / / \mathrm{h})$ & $1.0 \pm 0.1$ & $1.3 \pm 0.2$ & $1.8 \pm 0.4^{\mathrm{a}}$ \\
Serum adrenaline $(\mathrm{nmol} / \mathrm{l})$ & $0.21 \pm 0.04$ & $0.20 \pm 0.05$ & $0.19 \pm 0.02$ \\
Serum noradrenaline $(\mathrm{nmol} / \mathrm{l})$ & $1.3 \pm 0.1$ & $1.5 \pm 0.1^{\mathrm{b}}$ & $1.8 \pm 0.2^{\mathrm{b}}$ \\
Urinary dopamine $(\mathrm{nmol} / \mathrm{h})$ & $96 \pm 5$ & $91 \pm 4$ & $95 \pm 8$ \\
Atrial natriuretic peptide $(\mathrm{pmol} / \mathrm{l})$ & $10 \pm 1$ & $8 \pm 1$ & $11 \pm 2$ \\
\hline
\end{tabular}

Mean \pm SEM indicated

${ }^{a} \mathrm{p}<0.05$ vs basal and ${ }^{b} \mathrm{p}<0.01$ vs basal

water. At 08.00 hours infusions of $20 \%$ para-amino-hippuric acid (PAH; Merck Sharp and Dohme, West Point, PA., USA; $0.2 \mathrm{ml} / \mathrm{kg}$ body weight, rate $-0.5 \mathrm{ml} / \mathrm{min}$ ) and $25 \%$ inulin (Inutest; Kemiflor, Stockholm, Sweden; $0.2 \mathrm{ml} / \mathrm{kg}$ body weight, rate $-0.5 \mathrm{ml} / \mathrm{min}$ ) were started through an indwelling cannula in a lower arm vein to estimate renal plasma flow (RPF) and glomerular filtration rate (GFR), respectively. After a 2 h equilibration period timed urine collections were started. To ensure adequate diuresis, $300 \mathrm{ml}$ of tap water was given orally each hour. During the study period the subjects were in the supine position, except when voiding urine. Systolic blood pressure, diastolic blood pressure and heart rate were measured every $45 \mathrm{~min}$ by standard methods. During the investigation, each subject kept one hand in a heated $\left(64^{\circ} \mathrm{C}\right)$ plexiglass box to permit sampling of arterialized venous blood [5]. The subjects voided urine every $45 \mathrm{~min}$ and urine samples were analysed for inulin, $\mathrm{PAH}$, lithium, dopamine and sodium. Blood samples for inulin, PAH, lithium, insulin, C-peptide, atrial natriuretic peptide (ANP), plasma renin activity, adrenaline, noradrenaline, blood glucose, haematocrit and sodium were taken after each clearance period. After two basal $45-\mathrm{min}$ clearance periods, insulin was infused $\left(400 \mathrm{mU} \cdot \mathrm{ta}^{2}\right.$ as a bolus, followed by $20 \mathrm{mU} \cdot \mathrm{m}^{-2} \cdot \mathrm{min}^{-1}$ ) for three 45 -min clearance periods. Insulin (Insulin Actrapid 100 U/l; Novo, Bagsværd, Denmark) was dissolved in $48 \mathrm{ml} \mathrm{NaCl}(154 \mathrm{mmol} / \mathrm{l})$ and $2 \mathrm{ml}$ of the patient's blood and was infused through an antecubital vein. Arterialized blood samples were drawn from a plastic catheter placed in a forearm vein in the same arm. The fasting blood glucose level was maintained by adjustment of the infusion rate of a $20 \%$ glucose solution. Blood glucose was measured every $5 \mathrm{~min}$ with an automated glucose oxidase method (Glucose analyzer II; Beckman Instruments AB, Fullerton, Calif., USA). On a second study day, after an interval of at least 2 weeks the protocol was repeated in the same ten subjects with the exception that insulin was given in a higher dose $\left(800 \mathrm{mU} \cdot \mathrm{m}^{2}\right.$ as a bolus, followed by $40 \mathrm{mU} \cdot \mathrm{m}^{-2} \cdot \mathrm{min}^{-1}$ ).

\section{Calculations}

Mean arterial pressure was calculated as the diastolic blood pressure plus one third of the pulse pressure. Sodium, inulin, PAH and lithium clearances were calculated employing the usual formulas. The means of the inulin, PAH, lithium and sodium values at the beginning and end of each clearance period were used for the clearance calculations. The filtration fraction was determined by GFR/RPF as estimated by the inulin and $\mathrm{PAH}$ clearances, respectively. The method of lithium clearance described by Thomsen [6] is based on two assumptions: (1) lithium is reabsorbed in the proximal tubule in parallel with sodium and water, and (2) lithium is neither secreted nor reabsorbed beyond the proximal tubules. Hence, the fractional proximal tubular reabsorption of sodium was calculated as 1$\left(\mathrm{C}_{\mathrm{L}} / \mathrm{C}_{\mathrm{In}}\right) \times 100 \%$ and the fractional distal tubular sodium reabsorptions as $1-\left(\mathrm{C}_{\mathrm{Na}} / \mathrm{C}_{\mathrm{Li}}\right) \times 100 \%$. The absolute proximal tubular reabsorption of sodium was calculated as $\mathrm{P}-\mathrm{Na} \cdot\left(\mathrm{C}_{\mathrm{In}}-\mathrm{C}_{\mathrm{Li}}\right) \mathrm{mmol} / \mathrm{min}$ and the absolute distal reabsorption of sodium was calculated as $\mathrm{P}-\mathrm{Na} \cdot\left(\mathrm{C}_{\mathrm{U}}-\mathrm{C}_{\mathrm{Na}}\right) \mathrm{mmol} / \mathrm{min}$.

\section{Analyses}

Urinary dopamine and serum levels of noradrenaline and adrenaline were analysed as previously described [7]. Specific radioimmunoassays were used to analyse ANP [8], C-peptide [9] and plasma insulin [10]. Plasma renin activity was analysed with a commercial kit (Phadebas ANG-I test; OY Medix, Helsinki, Finland). The detection limit of the plasma renin activity assay was $0.3 \mu \mathrm{g} \cdot \mathrm{l}^{-1} \cdot \mathrm{h}^{-1}$. Values less than $0.3 \mu \mathrm{g} \cdot \mathrm{l}^{-1} \cdot \mathrm{h}^{-1}$ were treated as equal to $0.3 \mu \mathrm{g} \cdot \mathrm{I}^{-1} \cdot \mathrm{h}^{-1}$. Serum and urinary concentrations of lithium were measured by atomic absorption (Modell IL 751 AA Spectrophotometer; Instrumental Laboratory Inc., Wilmington, Del,, USA) using the method previously described by Amdisen [11] with the exception that protein was precipitated with $\mathrm{HNO}_{3}$. To correct for the precipitation of protein, serum lithium concentrations were multiplied by a factor of 0.965 . Determinations of blood glucose, haematocrit and sodium were made in the Department of Clinical Chemistry, Huddinge Hospital, employing routine methods.

\section{Statistical analysis}

Reported data represent the means of repeated measurements during basal conditions and during hyperinsulinaemia, respectively, as described above. There was no statistically significant difference between data obtained during basal conditions prior to the low- and high-dose insulin infusions ( $p>0.73$ for all parameters), and the means of data from the two study periods were therefore used for the analyses. All data are given as means \pm SEM. Non-parametric statis- 
Table 3. Effects of insulin infusions on renal haemodynamics and urine flow rate

\begin{tabular}{lccc}
\hline & Basal & Low-dose insulin & High-dose insulin \\
\hline Glomerular filtration rate (ml/min) & $111 \pm 4$ & $107 \pm 3$ & $110 \pm 4$ \\
Renal plasma flow (ml/min) & $571 \pm 15$ & $618 \pm 25$ & $630 \pm 19^{\mathrm{a}}$ \\
Filtration fraction $(\%)$ & $19.5 \pm 0.9$ & $18.2 \pm 0.9^{\mathrm{a}}$ & $17.2 \pm 0.8^{\mathrm{b}}$ \\
Urine flow rate $(\mathrm{ml} / \mathrm{min})$ & $5.7 \pm 0.4$ & $5.8 \pm 0.5$ & $6.3 \pm 0.3$ \\
\hline
\end{tabular}

Mean \pm SEM indicated

${ }^{a} p<0.05$ vs basal and ${ }^{b} p<0.01$ vs basal

Table 4. Effects of insulin infusions on renal sodium and lithium clearance and calculated proximal and distal tubular sodium handling

\begin{tabular}{|c|c|c|c|}
\hline & Basal & Low-dose insulin & High-dose insulin \\
\hline Renal sodium clearance $(\mathrm{ml} / \mathrm{min})$ & $1.6 \pm 0.1$ & $1.2 \pm 0.1^{2}$ & $1.0 \pm 0.1^{b}$ \\
\hline Renal lithium clearance ( $\mathrm{ml} / \mathrm{min})$ & $30.0 \pm 1.1$ & $31.3 \pm 2.3$ & $33.7 \pm 0.8^{b}$ \\
\hline Absolute proximal sodium reabs. (mmol/min) & $11.3 \pm 0.5$ & $11.0 \pm 0.6$ & $9.8 \pm 0.6^{\mathrm{d}}$ \\
\hline Fractional proximal sodium reabs. $(\%)$ & $73.7 \pm 1.1$ & $71.4 \pm 1.7$ & $68.2 \pm 1.5^{\mathrm{a}}$ \\
\hline Absolute distal sodium reabs. (mmol/min) & $3.8 \pm 0.1$ & $4.1 \pm 0.3$ & $4.5 \pm 0.1^{b}$ \\
\hline Fractional distal sodium reabs $(\%)$ & $94.8 \pm 0.4$ & $96.4 \pm 0.3^{b}$ & $97.3 \pm 0.2^{\mathrm{b}, \mathrm{s}}$ \\
\hline
\end{tabular}

Mean \pm SEM indicated

${ }^{a} \mathrm{p}<0.05$ vs basal, ${ }^{b} \mathrm{p}<0.01$ vs basal, ${ }^{\mathrm{c}} \mathrm{p}<0.01$ vs low-dose insulin and ${ }^{d} \mathrm{p}=0.06$ vs basal

tics were applied. The Friedman two-way analysis of ranks and the Wilcoxon matched-pairs signed-ranks test were used to test changes from and between basal values and low-dose and high-dose insulin infusions, respectively. $P$ values less than 0.05 were considered to be statistically significant.

\section{Results}

All results are shown in Tables 1-4. Following insulin infusions at a rate of $20 \mathrm{mU} \cdot \mathrm{m}^{-2} \cdot \mathrm{min}^{-1}$ (low-dose insulin) and $40 \mathrm{mU} \cdot \mathrm{m}^{-2} \cdot \mathrm{min}^{-1}$ (high-dose insulin), the mean plasma insulin concentrations rose to $41 \pm 3 \mathrm{mU} / \mathrm{l}$ and $90 \pm 7 \mathrm{mU} / \mathrm{l}$, respectively. The mean plasma insulin levels in each insulin clamp period are shown in Figure 1. The coefficient of variation for plasma insulin levels was $15 \%$ following the low-dose insulin infusion and $22 \%$ following the high-dose insulin infusion. There was a similar and significant $(p<0.01)$ fall in C-peptide levels from $0.50 \pm 0.04$ to $0.34 \pm 0.04 \mathrm{nmol} / 1$ in response to both the low-dose and the high-dose insulin infusions. Euglycaemia $(4.5 \pm 0.1 \mathrm{mmol} / \mathrm{l})$ was maintained and the coefficient of variation for the plasma glucose concentrations was $6.2 \%$ following the low-dose insulin infusion and $5.5 \%$ following high-dose insulin infusion. There was a rise in heart rate from $54 \pm 2$ beats per min in the basal state to $58 \pm 2$ beats per min (NS) following the low-dose insulin infusion, and to $59 \pm 4$ beats per $\min (p<0.05)$ following the high-dose insulin infusion. There were no significant changes in systolic or diastolic or mean arterial blood pressures in response to either of the insulin infusions (Table 1 ).

A significant $(p<0.05) 80 \%$ rise in plasma renin activity was observed following the high-dose insulin infusion. Significant increases $(p<0.01)(15 \%$ and $38 \%$, respectively) in noradrenaline levels were seen in response to both the low-dose and the high-dose insulin infusions (Table 2) but serum adrenaline levels were not affected. Renal dopamine mobilisation, as estimated from the urinary excretion of dopamine, and plasma levels of ANP did not change from the basal level following either the lowor the high-dose insulin infusion (Table 2). Data on renal haemodynamic parameters during basal conditions and following insulin infusions are presented in Table 3. A significant $(p<0.05) 10 \%$ rise in renal plasma flow was seen following the high-dose insulin infusion whereas GFR was unchanged. The time- and dose-dependent changes in renal plasma flow following low and high-dose insulin infusions are shown in Figure 2. Significant decreases in filtration fraction were seen following both insulin infusions. There was a small non-significant rise in the urine flow rate following the high-dose insulin infusion.

The change in the renal clearance of sodium is presented in Table 4 and the time- and dose-dependent falls in sodium clearance are shown in Figure 3. Following the high-dose insulin infusion there was a significant rise $(p<0.01)$ in lithium clearance from $30.0 \pm 1.1$ to

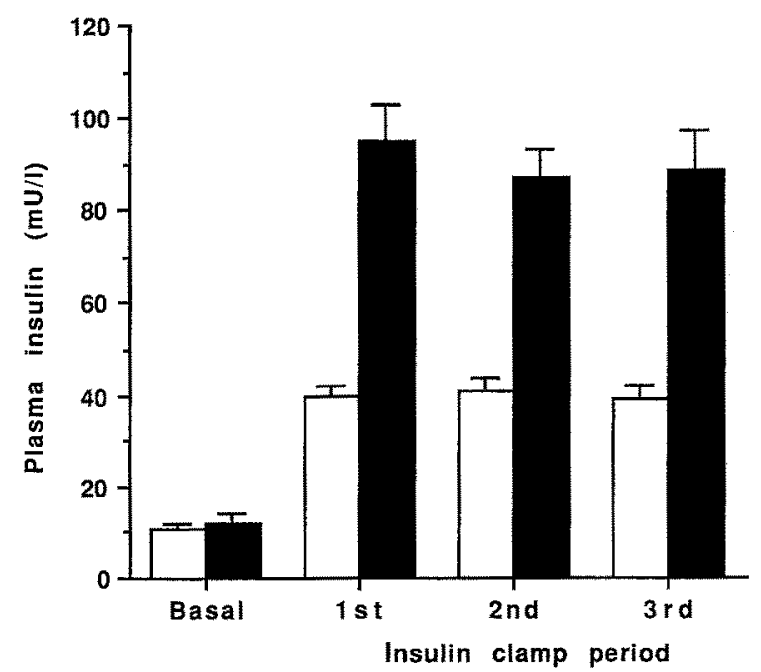

Fig. 1. Plasma insulin levels in the basal state and in the three insulin clamp clearance periods following low-dose insulin infusion ( $\square$ ) and high-dose insulin infusion ( $\mathbf{a})$ 


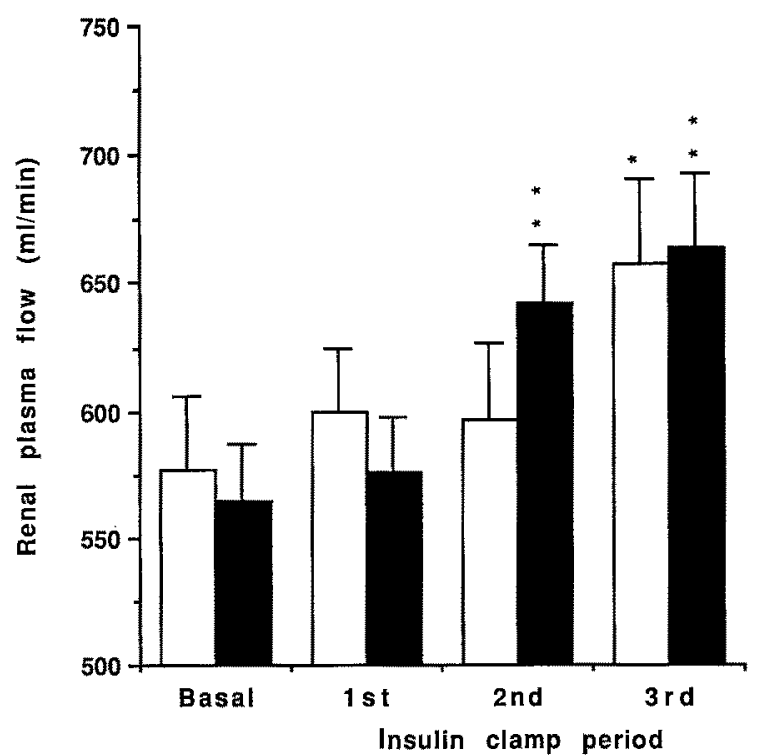

Fig. 2. Effect of hyperinsulinaemia on renal plasma flow over time. Low-dose insulin infusion ( $\square$ ) and high-dose insulin infusion ( $\mathbf{\square}$ ). Abscissa: Basal and 1st to 3rd insulin clamp period. ${ }^{*} p<0.05$ and $* * p<0.01$ vs basal

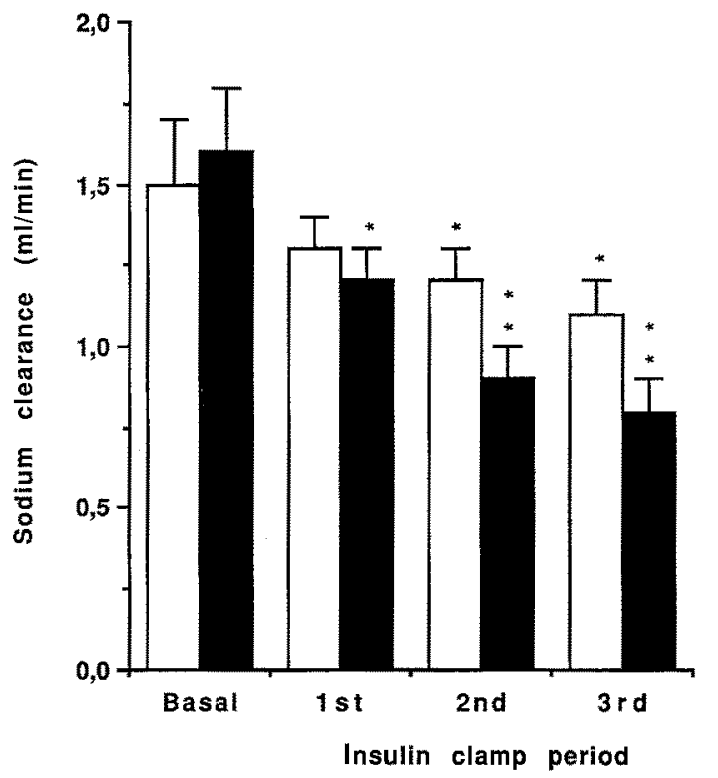

Fig. 3. Effect of hyperinsulinaemia on sodium clearance over time. Low-dose insulin infusion ( $\square$ ) and high-dose insulin infusion ( $\mathbf{a}$ ). Abscissa: Basal and 1st to 3 rd insulin clamp period. $* p<0.05$ and $* * p<0.01$ vs basal

$33.7 \pm 0.8 \mathrm{ml} / \mathrm{min}$. Fractional distal sodium reabsorption increased significantly $(p<0.01)$ in response to both the low- and high-dose insulin infusions to $96.4 \pm 0.3 \%$ and $97.3 \pm 0.2 \%$, respectively, as compared to $94.8 \pm 0.4 \%$ in the basal state. A significant $(p<0.01)$ increase in the absolute distal tubular sodium reabsorption from $3.8 \pm 0.1$ to $4.5 \pm 0.1 \mathrm{mmol} / \mathrm{min}$ following the high-dose insulin infusion was seen. The time- and dose-dependent increases in the absolute distal sodium reabsorption in response to low- and high-doses of insulin are shown in Figure 4. The fractional proximal sodium reabsorption declined $(p<0.05)$ in response to high-dose insulin infusion from $73.7 \pm 1.1$ to $68.2 \pm 1.5 \%$. The decrease in the absolute proximal tubular sodium reabsorption that was seen following high-dose insulin infusion did not reach statistical significance $(p=0.06)$. However, a gradual decrease over time in the absolute proximal tubular sodium reabsorption was observed in response to the high level of insulin infusion, as shown in Figure 5.

\section{Discussion}

The present results confirm previous observations of a reduced sodium excretion following an acute increase in plasma insulin levels $[1-4,12,13]$. The plasma insulin levels recorded during the low-dose insulin infusion $(41 \pm 3 \mathrm{mU} / \mathrm{l})$ correspond to those observed postprandially in normal man and caused a $25 \%$ reduction in sodium clearance. When the plasma insulin levels were raised to a submaximal physiological level $(90 \pm 7 \mathrm{mU} / \mathrm{l})$, a $40 \%$ reduction in sodium clearance was noted, suggesting that insulin causes an acute dose-dependent reduction in sodium excretion. The enhanced reabsorption of sodium following the insulin infusion in the present study was seen in conjunction with an unaffected GFR indicating, in agreement with previous observations, that the hormone directly stimulates sodium uptake at a tubular site $[2,3]$. However, the tubular site of the antinatriuretic effect of insulin has been the subject of controversy. In dogs studied by the recollection micropuncture technique, insulin infusions leading to high physiological or supraphysiological plasma insulin levels reduced the urinary sodium excretion by $35-50 \%$ by stimulating the distal tubular reabsorption. This occurred concomitantly with a significant decline in proximal tubular sodium reabsorption [1]. In contrast to this finding, insulin was observed to stimulate sodium reabsorption in rabbit proximal tubules studied by in vitro microperfusion [14]. Conflicting results have also been reported in human studies using lithium clearance to localize the insulin effect. Observations by Skøtt et al. [2], Friedberg et al. [3] and Nørgaard et al. [4] indicate that physiological insulin levels stimulate sodium reabsorption at a distal tubular site, whereas the results of Trevisan et al. [15] suggest that insulin produces its antinatriuretic effect in the proximal tubule.

In the present study, we used the renal lithium clearance technique to measure the output of sodium from the proximal tubules. The limitations of the lithium clearance technique have been discussed by others $[16,17]$. Since blood glucose was kept constant and normal during the insulin infusion and the subjects were adequately hydrated and sodium-repleted during the experiments, glucosuria, dehydration and sodium depletion can be excluded as potential confounding factors. The increase in lithium clearance during insulin infusion, as shown in the present study, was therefore most probably due to a direct or indirect effect of insulin on the proximal tubule, although it cannot be excluded that a part of the increase in lithium excretion seen following the insulin infusion was due to inhibition of lithium reabsorption in Henle's loop. However, since Kirchner et al. [18] found that the insulin infusion 

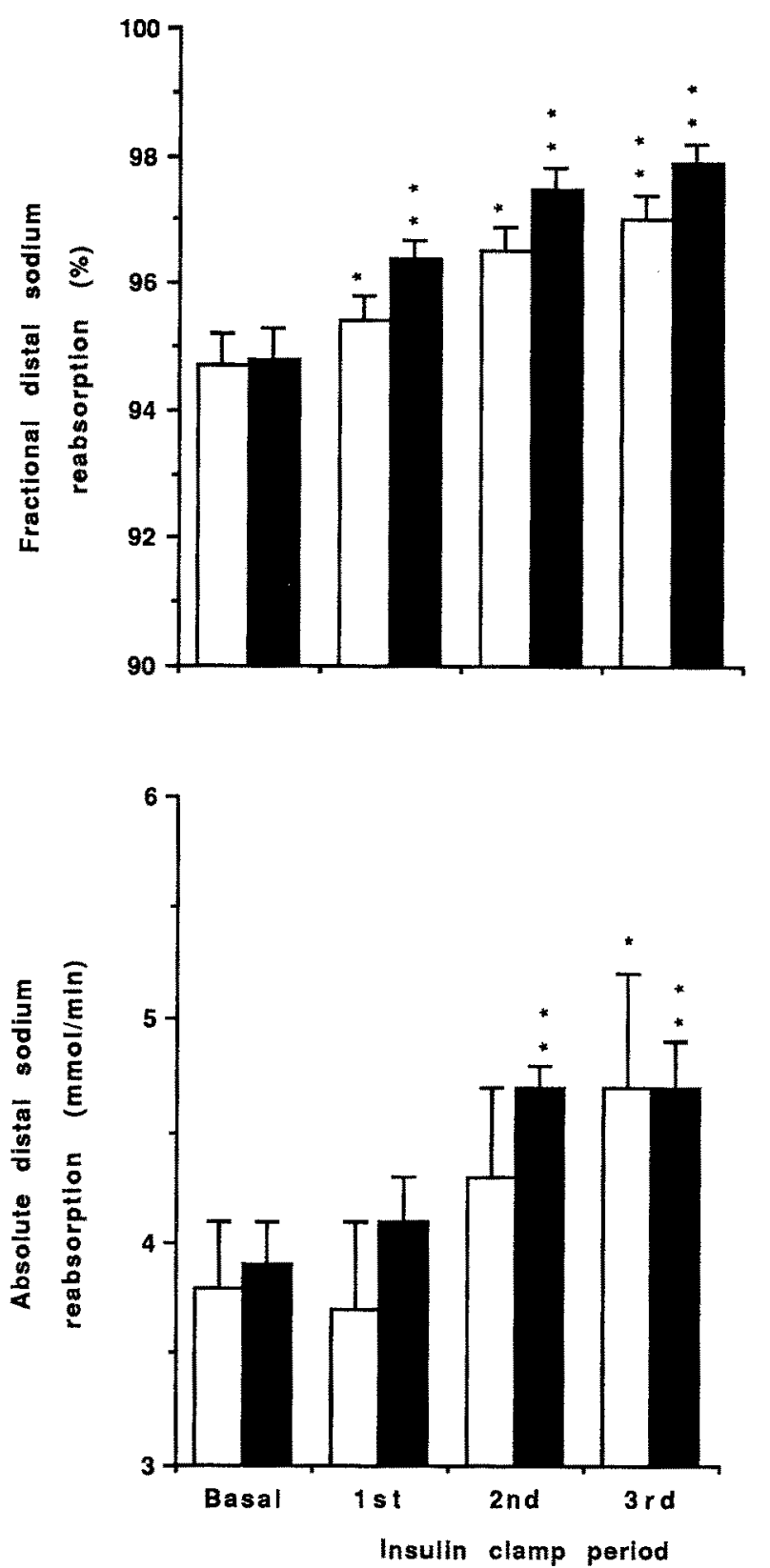

Fig.4. Effect of hyperinsulinaemia on fractional (top) and absolute (bottom) distal tubular sodium reabsorption over time. Low-dose insulin infusion ( $\square$ ) and high-dose insulin infusion ( $)$. Abscissa: Basal and 1st to 3rd insulin clamp period. ${ }^{*} p<0.05$ and ${ }^{* *} p<0.01$ vs basal

stimulated chloride reabsorption in Henle's loop and since it is believed that sodium and lithium are transported in the same direction in those segments where both are handled, the latter possibility seems unlikely. Our results indicate that insulin causes sodium retention by a dose-dependent stimulatory effect on sodium reabsorption in the distal tubule, as evaluated by both an increase in the absolute $(\mathrm{mmol} / \mathrm{min})$ and fractional (\%) distal sodium reabsorption, using the lithium clearance technique. A distal tubular effect of insulin accords with the observation that this part of the nephron exhibits the highest density of insulin receptors [19]. Moreover, insulin stimulates $\mathrm{Na}^{+} \mathrm{K}^{+}$ATPase [20], a cation transport system which is
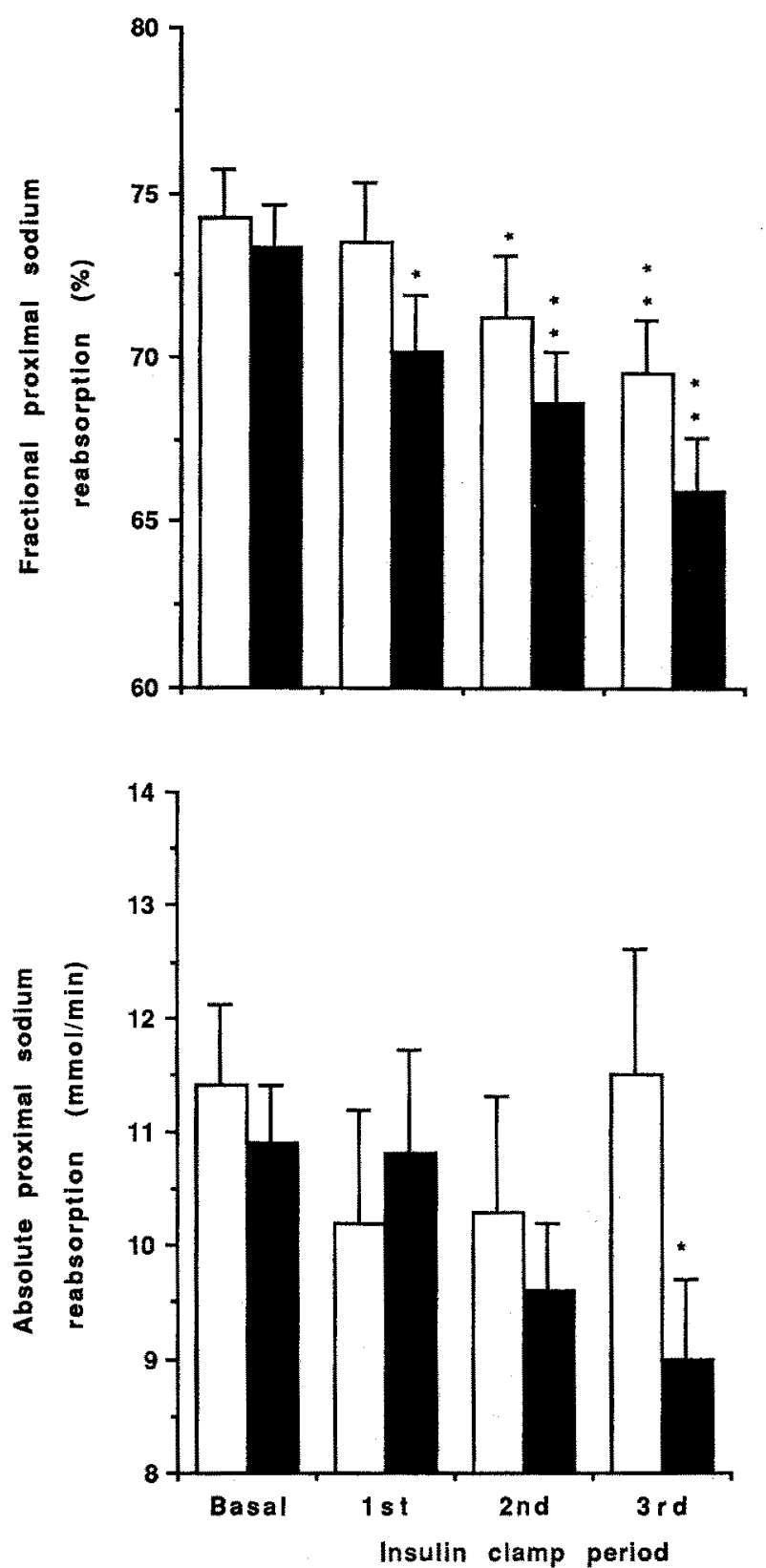

Fig.5. Effect of hyperinsulinaemia on fractional (top) and absolute (bottom) proximal tubular sodium reabsorption over time. Lowdose insulin infusion ( $\square$ ) and high-dose insulin infusion ( $\square$ ). Abscissa: Basal and 1st to 3rd insulin clamp period. $* p<0.05$ and $* * p<0.01$ vs basal

abundant in the distal tubules [21]. The receptors are located at the basolateral aspect of the tubules accessible from the blood stream and there is an excellent correlation between $\mathrm{Na}^{+} \mathrm{K}^{+}$ATPase-activity and the reabsorptive capacity in the distal tubules [22].

The present study indicates that physiological hyperinsulinaemia causes a gradual decline in the proximal tubular sodium reabsorption in conjunction with a stimulated distal tubular sodium reabsorption. This is in accordance with the micropuncture findings in dogs by DeFronzo et al. [1] and the increase in lithium clearance found by Friedberg et al. [3] but in contrast to the unchanged lithium clearance seen in the study by Skøtt et al. 
[2]. The discrepancy between our results and those of Skøtt et al. may depend on differences in the experimental protocols and in the dose of insulin given. In the present study the effects of low- and high-dose insulin infusions were determined during three consecutive clearance periods of $45 \mathrm{~min}$ each, and we observed a dose- and time-dependent effect of insulin on both the distal and proximal sodium handling, although in opposite directions. Significant increases in distal sodium reabsorption were observed during the first 45 -min clearance period after induction of both levels of hyperinsulinaemia. However, it should be noted that whereas the higher plasma insulin level resulted in a prompt decrease in the fractional proximal tubular sodium reabsorption, there was a delayed attenuation of the fractional proximal sodium reabsorption in response to the lower insulin dose and a statistically significant change from basal values was not observed until the second 45-min clearance period after induction of hyperinsulinaemia. This suggests that there was a time-lag between the increase in distal sodium reabsorption and the attenuation of proximal sodium reabsorption, the delay being more pronounced at the lower level of hyperinsulinaemia. It is therefore tempting to speculate that insulin-stimulated distal sodium reabsorption resulting in sodium retention and expansion of the extracellular fluid volume led to inhibition of proximal sodium reabsorption. While insulin has been shown to increase the proximal sodium reabsorption in studies performed in vitro $[14,23$, 24], studies performed in vivo have failed to demonstrate increased proximal tubular sodium reabsorption in response to insulin in humans [2-4], dogs [1] or rats [18]. The reason for the discrepancy between the in vitro and in vivo effects of insulin on proximal sodium reabsorption remains unclear. If the antinatriuretic action of insulin were to be sustained, expansion of the extracellular volume would ensue, and inhibition of the proximal tubular sodium reabsorption might be a mechanism present only in the intact animal which protects it from the sodium-retaining effects of insulin. Indeed, neither essential hypertension nor obesity are characterized by increased total body exchangeable sodium $[25,26]$ while increased total exchangeable sodium is a typical finding in diabetes [27]. Moreover, studies in dogs have shown that chronic hyperinsulinaemia induced by insulin infusion for 7 days fails to cause hypertension and, following a decrease in sodium excretion during the first 2-3 days, natriuresis returns towards basal values by an "escape-mechanism" of unknown aetiology [28].

Information is limited concerning the effects of acute insulin infusion on endogenous natriuretic factors, such as renal dopamine and ANP. Renal dopamine stimulates sodium excretion by a rapid and reversible inhibition of $\mathrm{Na}^{+} \mathrm{K}^{+}$ATPase in the proximal tubule [29]. The renal mobilisation of dopamine, as reflected by urinary dopamine excretion, was not affected by hyperinsulinaemia in the present study, rendering a dopamine-mediated inhibition of proximal sodium reabsorption unlikely. In a previous study by Trevisan et al. [15], insulin administration for $24 \mathrm{~h}$ raised ANP levels in non-diabetic subjects whereas in the present study plasma ANP levels were not affected by hyperinsulinaemia for $2 \mathrm{~h}$ and $15 \mathrm{~min}$, thus suggesting that the ANP changes are secondary to plasma expansion and not to insulin itself. Our results suggest that ANP does not mediate the fall in proximal tubular sodium reabsorption following insulin infusion. In the present study hyperinsulinaemia within the moderately high to submaximal physiological range resulted in unchanged systemic blood pressure and GFR, significantly increased renal plasma flow and reduced the filtration fraction, indicating a direct vasodilatory effect of insulin similar to the vasodilatory effect of angiotensin-converting enzyme inhibition. Cohen et al. [30] have shown that insulin has a significant renal vasodilatory effect and that the vasoconstrictor response to angiotensin II can be attenuated by physiological hyperinsulinaemia in the isolated rat kidney. Direct vasodilatory properties of insulin have previously been demonstrated in vitro [31] and vasodilatation has also been observed in human skeletal muscle following hyperinsulinaemia [32]. One can speculate that the observed renal vasodilatation resulted in a fall in the proximal tubular sodium reabsorption, possibly mediated by changes in the renal interstitial pressure $[33,34]$. The increases in serum levels of noradrenaline and heart rate observed in the present study agree with the findings by Rowe et al. [35] and may be a secondary reflex phenomenon to compensate for a fall in systemic vascular resistance.

In conclusion, the present study demonstrates that insulin produces an acute dose-dependent antinatriuretic effect by stimulating distal tubular sodium reabsorption. Under the present experimental conditions hyperinsulinaemia is also associated with decreased proximal sodium reabsorption. The mechanism(s) causing the fall in proximal tubular sodium reabsorption are not clear. The present data do not support the concept of a contributory role of ANP or of renal dopamine. However, in view of the observed increases in renal plasma flow, renal vasodilatation following the induction of hyperinsulinaemia could have contributed to this alteration. If the attenuation of the proximal sodium reabsorption is maintained during chronic hyperinsulinaemia, this could be a counter-regulatory mechanism balancing the antinatriuretic effect of insulin in the distal tubule and thus preventing expansion of the extracellular fluid volume.

Acknowledgements, We thank Ms E.Digreus, Ms U.Petterson and the staff of the Clinical Physiological Laboratory for their help with the clamp study and Ms A-M. Forsberg and Ms E. Nilsson for analysis of lithium. This study was supported by a grant from Nordisk Insulin, Denmark.

\section{References}

1. DeFronzo RA, Goldberg M, Agus Z (1976) The effects of glucose and insulin on renal electrolyte transport. J Clin Invest 58: $83-90$

2. Sk $\varnothing t t$ P, Hother-Nielsen O, Bruun NE, Giese J, Beck-Nielsen H, Parving HH (1989) Effects of insulin on kidney function and sodium excretion in healthy subjects. Diabetologia 32:694-699

3. Friedberg CE, van Buren M, Bijlsma JA, Koomans HA (1991) Insulin increases sodium reabsorption in diluting segment in humans: evidence for indirect mediation through hypokalemia. Kidney Int 40: 251-256 
4. Nørgaard K, Jensen T, Skøtt P et al. (1991) Effects of insulin on renal hemodynamics and sodium handling in normal subjects. Scand J Clin Lab Invest 51: 367-376

5. Abumrad N, Rabin D, Diamond M, Lacy W (1981) Use of a heated superficial hand vein as an alternative site for the measurement of amino acid concentrations and for the study of glucose and alanine kinetics. Metab Clin Exp 30: 936-940

6. Thomsen K (1984) Lithium clearance: a new method for determining proximal and distal reabsorption of sodium and water. Nephron 37:217-223

7. Stenvinkel P, Saggar-Malik AK, Wahrenberg H, Diczfalusy U, Bolinder J, Alvestrand A (1991) Impaired intrarenal dopamine production following intravenous sodium chloride infusion in type 1 (insulin-dependent) diabetes mellitus. Diabetologia 34: 114118

8. Andersson U, Sylvén C, Lindvall K, Theodorsson E, Norée L-O (1988) Cardiac function and cardiovascular hormone balance during hemodialysis with special reference to atrial natriuretic peptide. Clin Nephrol 30: 303-307

9. Heding LP (1975) Radioimmunological determination of human C-peptide in serum. Diabetologia 11:541-548

10. Wide L, Axén R, Porath J (1967) Radioimmunosorbent assay for proteins chemical couplings of antibodies to insoluble dextran. Immunochemistry 4: 381-386

11. Amdisen $A(1975)$ The estimation of lithium in urine. In Johnson FN (ed) Lithium research and therapy. Academic Press, London, pp 181-195

12. DeFronzo RA, Cooke CR, Andres R, Falonna GR, Davis PJ (1975) The effect of insulin on renal handling of sodium, potassium, calcium and phosphate in man. J Clin Invest 55: 845-855

13. Gans ROB, Bilo HJG, Nauta JJP, Poop-Snijders C, Heine RJ, Donker AJM (1991) Renal and cardiovascular effects of exogenous insulin in healthy volunteers. Clin Sci $80: 219225$

14. Baum M (1987) Insulin stimulates volume absorption in the rabbit proximal convoluted tubule. J Clin Invest 79: 1104-1109

15. Trevisan R, Fioretti P, Semplicini A et al. (1990) Role of insulin and atrial natriuretic peptide in sodium retention in insulintreated IDDM patients during isotonic volume expansion. Diabetes 39: 289-298

16. Skøtt P, Bruun NE, Giese J, Holstein-Rathlou NH, Leyssac PP (1987) What does lithium clearance measure during osmotic diuresis? Clin Sci 73: 126-127

17. Koomans HA, Boer WH, Dorhout Mees EJ (1989) Evaluation of lithium clearance as a marker of proximal tubule sodium handling. Kidney Int 36: 2-12

18. Kirchner KA (1988) Insulin increases loop segment chloride reabsorption in the euglycaemic rat. Am J Physiol 255: F1206F1213

19. Rabkin R, Ryan MP, Duckworth WC (1984) The renal metabolism of insulin. Diabetologia 27: 351-357

20. Moore RD (1983) Effect of insulin upon fon transport. Biochem Biophys Acta 737:1-49

21. Jørgensen PL (1980) Sodium and potassium ion pump in kidney tubules. Physiol Rev 60:864-917
22. Madsen KM, Tischer TC (1986) Structural-functional relationships along the distal nephron. Am J Physiol 250: F1-F15

23. Fine LG, Badie-Dezfooly B, Lowe AG, Hamzeh A, Wells J, Salehmoghaddam $\mathrm{S}(1985)$ Stimulation of $\mathrm{Na}+/ \mathrm{H}+$ antiport is an early event in hypertrophy of renal proximal tubular cells. Proc Natl Acad Sci USA 82: 1736-1740

24. Gesek FA, Schoolwerth AC (1991) Insulin increases $\mathrm{Na}^{+}-\mathrm{H}^{+}$exchange activity in proximal tubules from normotensive and hypertensive rats. Am J Physiol 260: F695-F703

25. Berretta-Piccoli C, Davies DL, Boddy K et al. (1982) Relation of arterial pressure with body sodium, body potassium and plasma potassium in essential hypertension. Clin Sci $63: 257-270$

26. Boehringer K, Beretta-Piccoli C, Weidmann P, Meier A, Ziegler WH (1982) Pressor factors and cardiovascular pressor responsiveness in lean and overweight normal or hypertensive subjects. Hypertension 4: 697-702

27. De Chatel R, Weidemann R, Flammer J et al. (1977) Sodium, renin, aldosterone, catecholamines and blood pressure in diabetes mellitus. Kidney Int 12: 412-421

28. Hall JE, Brands MW, Mizelle HL, Gaillard CA, Hildebrandt DA (1991) Chronic intrarenal hyperinsulinaemia does not cause hypertension. Am J Physiol 260: F663-F669

29. Aperia A, Bertorello A, Seri I (1987) Dopamine causes inhibition of $\mathrm{Na}^{+}-\mathrm{K}^{+}-$ATPase activity in rat proximal convoluted tubule segments. Am J Physiol 252: F39-F45

30. Cohen AJ, McCarthy DM, Stoff JS (1989) Direct hemodynamic effect of insulin in the isolated perfused kidney. Am J Physiol 257: F580-F585

31. Alexander WD, Oake RJ (1977) The effect of insulin on vascular reactivity to norepinephrine. Diabetes 26:611-614

32. Laakso M, Edelman SV, Brechtel G, Baron AD (1990) Decreased effect of insulin to stimulate skeletal muscle blood flow in obese man. A novel mechanism for insulin resistance. $J$ Clin Invest $85: 1844-1852$

33. Haas JA, Granger JP, Knox FG (1986) Effect of renal perfusion pressure on proximal sodium reabsorption from proximal tubules of superficial and deep nephrons. Am J Physiol 250: F425F429

34. Haas JA, Hammond TG, Granger JP, Blaine EH, Knox FG (1984) Mechanism of natriuresis during intrarenal infusion of prostaglandins. Am J Physiol 247: F475-F479

35. Rowe JW, Young JB, Minaker KL, Stevens AL, Palotta J, Landsberg L (1981) Effect of insulin and glucose infusion on sympathetic nervous system activity in normal man. Diabetes 30:219-225

Received: 14 April 1992

and in revised form: 26 June 1992

Dr. P. Stenvinkel

Department of Renal Medicine K56

Huddinge University Hospital

S-141 86 Huddinge

Sweden 